\title{
Kapabilitas Pemasaran dalam Meningkatkan Kinerja Pemasaran pada Coffee Shop
}

\author{
Famela Sophya Suciati ${ }^{*}$ R Deni Muhammad Danial ${ }^{2}$, Asep Muhamad Ramdan ${ }^{3}$
}

1,2,3 Universitas Muhammadiyah Sukabumi, Sukabumi - Indonesia

\author{
A R T I C L E I N F O \\ Article history: \\ Received 15 April 2020 \\ Received in revised form \\ 14 May 2020 \\ Accepted 7 Jne 2020 \\ Available online 29 June \\ 2020 \\ Kata Kunci: \\ Kapabilitas Pemasaran; \\ Kinerja Pemasaran; Coffee \\ Shop \\ Keywords: \\ Marketing Capability; \\ Marketing Performance \\ Coffee Shop
}

\begin{abstract}
A B S T R A K
Tujuan pada riset ini yaitu untuk mengetahui pengaruh kapabilitas pemasaran dalam meningkatkan kinerja pemasaran. Metode pada riset ini menggunakan metode kuantitatif dengan pendekatan asosiatif. Riset ini menggunakan sampel sebanyak 37 coffee shop dengan pemilikya dijadikan sebagai responden. Teknik dalam rangka mengumpulkan sejumlah data yang dipergunakan untuk riset ini adalah data primer yaitu observasi, wawancara dan kuisioner serta data sekunder yang digunakan adalah studi kepustakaan. Riset ini melakukan pengujian untuk mengetahui valid dan reliabel data yang digunakan. Teknik untuk mengolah sejumlah data dilakukan dengan menggunakan uji koefisien korelasi, uji koefisien determinasi, uji regresi linear sederhana serta uji hipotesis yang digunakan yaitu uji signifikansi (Uji T). Simpulan pada riset ini menunjukkan bahwa adanya pengaruh signifikan dari variabel kapabilitas pemasaran terhadap kinerja pemasaran.
\end{abstract}

\section{A B S T R A C T}

The purpose of this research is to determine the effect of marketing capabilities in improving marketing performance. The method in this research uses a quantitative method with an associative approach. This research uses a sample of 37 coffee shops with the owner being the respondent. The technique in order to collect a number of data used for this research is primary data, namely observation, interviews and questionnaires and secondary data used is literature study. This research conducts testing to determine the valid and reliable data used. The technique to process a number of data is done using the correlation coefficient test, the coefficient of determination test, the simple linear regression test and the hypothesis test used is the significance test ( $\mathrm{T}$ test). The conclusions of this research indicate that there is a significant influence of the marketing capability variable on marketing performance.

Copyright ( () Ekuitas: Jurnal Pendidikan Ekonomi. All rights reserved. 


\section{Pendahuluan}

Meminum kopi sudah menjadi hal yang lumrah pada masyarakat sejak dahulu kala. Penikmat kopi di berbagai penjuru Indonesia merupakan dari berbagai usia baik dari usia remaja, orang yang sudah berusia dewasa bahkan hingga orang yang sudah lanjut usia (lansia). Hal tersebut menjadikan kopi sebagai konsumsi minuman yang dinikmati sehari-hari oleh masyarakat Indonesia (Chandra, 2018). Konsumsi kopi ini bukan hanya konsumsi kopi rumahan, tetapi juga pada usaha coffee shop. Semakin tingginya gaya hidup yang merajalela khususnya dikalangan anak muda, saat ini banyak yang berfikiran bahwa dengan mengunjungi coffee shop akan melengkapi gaya hidup pada seseorang dan meningkatkan eksistensi tersendiri bagi para pengunjung (Nurdianah, 2019).

Royan (dalam Lieberto, 2019) mengemukakan bahwa tingginya gaya hidup masyarakat saat ini menjadikan jumlah konsumsi kopi meningkat sebagaimana Badan Pusat Statistik menyatakan bahwa tingkat konsumsi kopi masyarakat Indonesia dari tahun 2015 sampai dengan tahun 2019 diproyeksikan meningkat sebesar $1,79 \mathrm{~kg} / \mathrm{kapita} /$ tahun. Hal tersebut dijadikan peluang bagi para pelaku usaha untuk mengembangkan usaha coffee shop karena banyaknya masyarakat yang berlomba-lomba untuk melengkapi gaya hidupnya. Berbeda halnya dengan coffee shop di Kota Sukabumi yang mengalami penurunan dari segi jumlah coffee shop seperti data yang didapatkan data dari Dinas Penanaman Modal dan Perizinan Terpadu Satu Pintu Kota Sukabumi yang menujukkan jumlah coffe shop pada tahun 2016 berjumlah sebanyak 48, lalu pada pada tahun 2017 mengalami penurunan sebesar $10.42 \%$ dengan jumlah sebanyak 43 dan pada tahun 2018 terus mengalami penurunan sebesar 13.95\% dengan jumlah menjadi 37.

Hasil yang didapatkan peneliti adalah kondisi coffee shop di Kota Sukabumi dalam menjalankan kinerja pemasaran yang dilakukan kurang baik, dikarenakan jumlah produk yang dijual oleh perusahaan mengalami penurunan serta jumlah pelanggan yang melakukan pembelian produk perusahaan pun mengalami penurunan secara terus menerus. Hal tersebut disebabkan oleh beberapa kendala yang dialami oleh coffee shop, yaitu kurangnya kemampuan coffee shop dalam mengelola kapabilitas pemasaran yang dapat dilihat dari ketidak mampuan coffee shop dalam memenuhi permintaan pasar yang sesuai dengan kebutuhan dan keinginan konsumen karena kurangnya kemampuan coffee shop dalam memanfaatkan sumber daya internal yang dimiliki secara produktif. Selanjutnya penyebab lain menurunnya jumlah coffee shop di Kota Sukabumi yaitu kurangnya kemampuan coffee shop dalam mendapatkan informasi tentang pelanggan dan pasar sehingga produk yang dipasarkan pun tidak sesuai dengan harapan dan kemauan konsumen yang sesuai dengan kondisi pasar yang sedang berlangsung. Selain itu banyak coffee shop yang tidak mampu mengidentifikasi pelanggan baru dan peluang pasar yang sedang berlangsung dengan baik sehinnga banyak coffee shop yang memasarkan produknya dengan kurang maksimal maksimal karena target yang dituju pun tidak sesuai dengan keadaan. Penyebab terakhir dari kurangnya pengeolaankapabilitas pemasaran yang baik yaitu coffee shop tidak mampu memperoleh informasi tentang pesaing sehingga banyak coffee shop yang tidak mengetahui hal yang tidak dimiliki oleh coffee shop lain yang membuat banyak coffee shop tidak memiliki keunggulan tersendiri yang mengakibatkan tidak mampu bersaing dengan para kompetitor lainnya. Data tersebut didapatkan dari hasil wawancara kepada sejumlah pemilik atau manajer coffee shop di Kota Sukabumi serta hasil dari kegiatan menyebarkan kuisioner. Ini mengkibatkan banyaknya coffee shop di Kota Sukabumi yang tidak mampu bertahan lama sehingga banyak coffee shop yang mengalami kebangkrutan.

Setiap menjalankan usaha, perusahaan harus memiliki kemampuan dalam memasarkan produk yang dihasilkan perusahaan dengan baik agar menciptakan kinerja pemasaran yang baik pula dan sesuai seperti tujuan yang dibuat perusahaan yaitu untuk menghasilkan keuntungan yang meningkat dari tahun sebelumnya secara maksimal bagi usaha (Hoiron, Wahyudi, \& Puspitaningtiyas, 2018).

Berdasarkan pemaparan permasalah yang dialami coffee shop di Kota Sukabumi, maka tujuan dalam penelitian yang dilakukan yaitu untuk mengetahui pengaruh kapabilitas pemasaran teradap kinerja pemasaran pada coffee shop.

Untuk lebih memahamimengenai variabel kapabilitas pemasaran dan kinerja pemasaran, maka dapat dijelaskan sebagai berikut: 


\section{1) Kapabilitas Pemasaran}

Kapabilitas pemasaran (marketing capabilities) merupakan serangkaian keterampilan yang dimiliki sumber daya perusaahaan dalam bidang pemasaran yang dikembangkan disuatu organisasi dalam menjalankan usaha dengan lebih baik (Hoiron et al., 2018). Ahmeda et. al, (dalamSyarifuddin, Payangan, Muis, \& Amar, 2019) mengemukakan bahwa kapabilitas pemasaran sebagai kemampuan untuk mempergunakan input dan sumber daya, seperti sumber daya keuangan dan basis pelanggan yang ada untuk digunakan menjadi lebih efisien dalam menghasilkan penjualan yang diinginkan. Maka dapat dirtarik kesimpulan bahwa dengan adanya kapabilitas pemasaran akan berpengaruh positif pada pertumbuhan suatu perusahaan ke arah yang lebih baik dengan cara memenuhi segala kebutuhan dalam menunjang keterampilan sumber daya menjadi lebih berkualitas khususnya keterampilan dalam melakukan kegiatan pemasaran. Sehingga akan sangat mudah bagi suatu perusahaan untuk menerapkan kapabilitas pemasaran dengan baik dalam menjalankan usahanya dengan mampu mengalahkan para pesaing dalam segi kegiatan pemasaran.

Untuk menjawab pertanyaan tentang kapabilitas pemasaran mana yang akan dibangun, Day dalam (Guo et al., 2018) mengidentifikasi tiga dimensi kapabilitas pemasaran:

1. Kapabilitas pemasaran statis, merupakan kemampuan dalam menggunakan sumber daya internal secara produktif untuk memenuhi permintaan pasar.

2. Kapabilitas pemasaran dinamis, yaitu kemampuan menyesuaikan kemampuan pemasaran sendiri dengan lingkungan pasar yang berubah-ubah.

3. Kapabilitas pemasaran adaptif, yaitu kemampuan untuk terlibat dalam pembelajaran pasar dengan cermat, eksperimen pasar yang dapat disesuaikan dengan keadaan, dan pemasaran terbuka melalui hubungan yang ditempa dengan mitra.

Terdapat beberapa dimensi kapabilitas pemasaran yang dikemukakan (Palacios-Marqués, García, Sánchez, \& Mari, 2019) yaitu sebagai berikut:

1. Informasi pelanggan dan pasar, adalah kemampuan perusahaan untuk mendapatkan berbagai keterangan maupun data mengenai pelanggan dan pasar saat ini.

2. Pelanggan baru dan peluang pasar, yaitu kemampuan perusahaan untuk mengidentifikasi adanya pelanggan baru dengan mampu membaca keinginan dan kebutuhan para pelanggan

3. Informasi pesaing, yaitu kemampuan perusahaan untuk mendapatkan berbagai informasi mengenai pesaing.

Berdasarkan pemaparan diatas, maka peneliti menyimpulkan dimensi pada kapabilitas pemasaran yang akan digunakan yaitu kapabilitas pemasaran statis, informasi pelanggan dan pasar, pelanggan baru dan peluang pasar, informasi pesaing Day (dalam Guo et al., 2018) dan (Palacios-Marqués et al., 2019).

\section{2) Kinerja Pemasaran}

Kinerja pemasaran adalah proses kegiatan yang dikerjakan perusahaan dalam memasarkan produk yang dihasilkan untuk dijadikan suatu ukuran sampai sejauh mana prestasi yang telah dicapai dalam memasarkan suatu produk dari kegiatan pemasaran yang dilakukan perusahaan (Rasyidi \& Sudjatno, 2016). Kinerja pemasaran adalah kunci keberhasilan suatu perusahaan apabila mampu menjalankan kegiatan pemasaran dengan baik dan benar dan dari kegiatan-kegiatan pemasaran tersebut, suatu perusahaan akan menjadikan itu sebagai acuan untuk mencapai prestasi (Hendrayati \& Gaffar, 2016). Sehingga dapat disimpulakan bahwa dengan menerapkan kinerja pemasaran dengan baik dan benar akan memudahkan suatu perusahaan untuk mencapai suatu prestasi dalam mencapai strategi pasar yang ditetapkan perusahaan, sehingga akan berpengaruh positif terhadap pendapatan perusahaan yang meningkat.

Kinerja pemasaran dapat dinyatakan melalui tiga dimensi yang dapat dijelaskan seperti dibawah (Rasyidi \& Sudjatno, 2016):

1. Volume penjualan, yaitu sejumlah hasil dari kegiatan penjualan suatu produk yang dihasilkan perusahaan dengan jangka waktu yang telah ditentukan. 
2. Tingkat pertumbuhan penjualan, yaitu kegiatan penjualan produk atau jasa yang mengalami peningkatan dimana perusahaan terus mengalami perkembangan dari periode sebelumnya.

3. Tingkat pertumbuhan pelanggan, yaitu sejumlah pencapaian yang diperoleh oleh suatu perusahaan dimana jumlah pelanggan mengalami pertambahan dari periode sebelumnya yang memberikan dampak positif bagi suatu perusahaan dari segi keuntungan yang meningkat.

Skala pengukuran kinerja pemasaran menggunakan tiga dimensi sebagaimana diajukan oleh Ferdinand (dalam Wirawan, 2017) diantaranya:

1. Pertumbuhan Penjualan, yaitu dimana perusahaan mengalami peningkatan penjualan produk dengan ditandai adanya para konsumen yang melakukan pembelian dalam jumlah yang banyak.

2. Pertumbuhan pelanggan, yaitu suaatu pencapaian yang berkaitan dengan sejauh mana perusahaan mampu meningkatkan jumlah konsumen dengan cara perusahaan sudah terlebih dahulu mengetahui dan memahami tingkat konsumsi rata-rata konsumen sehingga jumlah penjualan bias lebih dikembangkan.

3. Keberhasilan Produk, yaitu suatu pencapaian perusahaan yang ditunjukkan dari kinerja yang dicapai perusahaan dengan baik. Kinerja pada sebuah perusahaan dapat dikatakan baik apabila keberhasilan produk yang dihasilkan sebuah perusahaan pun baik.

Berdasarkan dari pernyataan para ahli diatas, maka peneliti menyimpulkan dimensi yang akan digunakan pada kinerja pemasaran yaitu tingkat pertumbuhan penjualan, tingkat pertumbuhan pelanggan, dan keberhasilan produk (Rasyidi \& Sudjatno, 2016) dan Ferdinand (dalam Wirawan, 2017).

\begin{tabular}{|c|c|}
\hline $\begin{array}{l}\text { Kapabilitas Pemasaran } \\
\quad \text { (X) } \\
\text { 1. Kapabilitas } \\
\text { Pemasaran Statis. } \\
\text { 2. Informasi Pelanggan } \\
\text { dan Pasar. } \\
\text { 3. Pelanggan baru dan } \\
\text { peluang pasar. } \\
\text { 4. Informasi pesaing. } \\
\\
\text { Day (dalam Guo et al., } \\
\text { 2018) dan (Palacios- } \\
\text { Marqués et al., 2019). }\end{array}$ & $\begin{array}{l}\text { Kinerja Pemasaran } \\
\text { (Y) } \\
\text { 1. Tingkat } \\
\text { pertumbuhan } \\
\text { penjualan. } \\
\text { 2. Tingkat } \\
\text { pertumbuhan } \\
\text { pelanggan. } \\
\text { 3. Keberhasilan produk. } \\
\text { (Rasyidi \& Sudjatno, } \\
\text { 2016) dan Ferdinand } \\
\text { (dalam Wirawan, 2017). }\end{array}$ \\
\hline
\end{tabular}

Gambar 1. Kerangka Pikir

Sumber: Data diolah peneliti, 2020

\section{Pengembangan Hipotesis}

Hipotesis pada penelitian ini, peneliti menetapkan bahwa terdapat pengaruh signifikan antara kapabilitas penelitian terhadap kinerja pemasaran. ini didukung berdasarkan penelitian terdahulu. Kapabilitas pemasaran berpengaruh positif terhadap kinerja pemasaran dapat diterima (Masrokan, Fathoni, \& Minarsih, 2016). Baik atau buruknya kinerja pemasaran secara positif disebabkan karena baik atau buruknya kapabilitas yang diberikan. Oleh karena itu setiap perusahaan harus memiliki kemampuan dalam memasarakan produk yang dimilikinya dengan baik seperti memberikan bentuk pelayanan terbaik sehingga akan memberikan dampak yang positif dalam pencapaian kinerja pemasaran pada usaha yang dijalankan perusahaan (Mawu, Mandey, \& Tawas, 2016). Selain itu, hasil penelitian (Hidayat \& Murwatiningsih, 2018) menyatakan bahwa terdapat pengaruh positif dan signifikan antara kapabilitas pemasaran terhadap kinerja pemasaran karena untuk meningkatkan kinerja pemasaran pada sebuah perusahaan, perusahaan harus memiliki kemampuan dalam bidang pemasaran yang kuat. 


\section{Metode}

Penelitian ini dilakukan pada coffee shop di Kota Sukabumi. Berdasarkan tujuan penelitian yang telah dikemukakan, maka jenis penelitian yang digunakan yaitu kuantitatif dengan pendekatan asosiatif. Penelitian asosiatif dilakukan untuk mengetahui penjelasan mengenai hubungan antara independent variable (kapabilitas pemasaran) terhadap dependent variable (kinerja pemasaran).

Untuk mendapatkan hasil perhitungan statistik, penelitian dibantu dengan menggunakan software IBM SPSS Statistic Version 23. Teknik pengumpulan data yang dilakukan menggunakan data primer, yaitu observasi dimana peneliti melakukan survei terhadap objek pada penelitian yang dilakukan, selain itu peneliti melakukan wawancara langsung dengan pemilik atau manajer coffee shop, serta menyebar kuesioner berupa pertanyaan yang sama kepada para pemilik atau manajer coffee shop dengan menggunakan skala likert. Adapun metode pengumpulan data sekunder yaitu dilakukan studi kepustakaan untuk membantu peneliti dalam mengumpulkan data melalui sumber-sumber yang ada hubungannya dengan permasalahan pada penelitian.

Populasi dalam penelitian ini yaitu pemilik atau manajer coffee shop di Kota Sukabumi dengan jumlah sampel sebanyak 37 coffee shop. Teknik sampel yang digunakan adalah sampling jenuh dimana seluruh pemilik atau manajer coffee shop di Kota Sukabumi dijadikan sebagai responden. Serta untuk mendapatkan data yang relevan, teknik pengolahan data yang dipergunakan dalam penelitian ini yaitu koefisien korelasi dan koefisien determinasi untuk memahami seberapa sebesar penelitian ini memiliki pengaruh, uji regresi linear sederhana karena penelitian yang digunakan hanya menggunakan satu variabel independen dan satu variabel dependen, serta uji signifikansi untuk mengetahui ada pengaruh atau tidaknya antara kapabilitas pemasaran terhadap kinerja pemasaran.

\section{Hasil dan pembahasan}

Tabel 1. Hasil Uji Validitas Kapabilitas Pemasaran (X)

\begin{tabular}{ccccc}
\hline No & Item & rhitung & rtabel & Keterangan \\
\hline 1 & $\mathrm{X} 1$ & 0.908 & 0.325 & Valid \\
\hline 2 & $\mathrm{X} 2$ & 0.919 & 0.325 & Valid \\
\hline 3 & $\mathrm{X} 3$ & 0.810 & 0.325 & Valid \\
\hline 4 & $\mathrm{X} 4$ & 0.871 & 0.325 & Valid \\
\hline
\end{tabular}

Sumber: Data diolah peneliti, 2020

Tabel 2. Hasil Uji Validitas Kinerja Pemasaran (Y)

\begin{tabular}{ccccc}
\hline No & Item & rhitung & Rtabel & Keterangan \\
\hline 1 & Y1 & 0.973 & 0.325 & Valid \\
\hline 2 & Y2 & 0.978 & 0.325 & Valid \\
\hline 3 & Y3 & 0.871 & 0.325 & Valid
\end{tabular}

Sumber: Data diolah peneliti, 2020

Dari hasil uji validitas diatas dapat diartikan bahwa kapabilitas pemasaran (X) dan kinerja pemasaran (Y) dinyatakan berstatus valid, karena nilai dari $r_{\text {hitung }}$ lebih besar dari $r_{\text {tabel. }}$. 
Tabel 3. Hasil Uji Reliabilitas Kapabilitas Pemasaran (X)

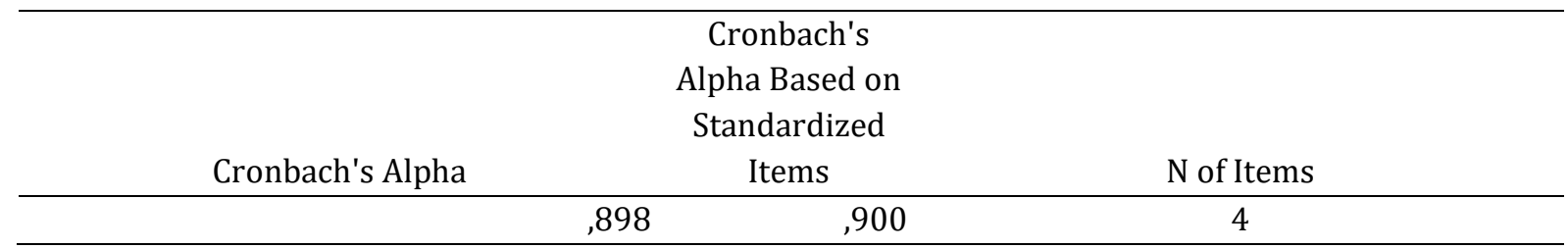

Sumber: Data diolah peneliti, 2020

Tabel 4. Hasil Uji Reliabilitas Kinerja Pemasaran (Y)

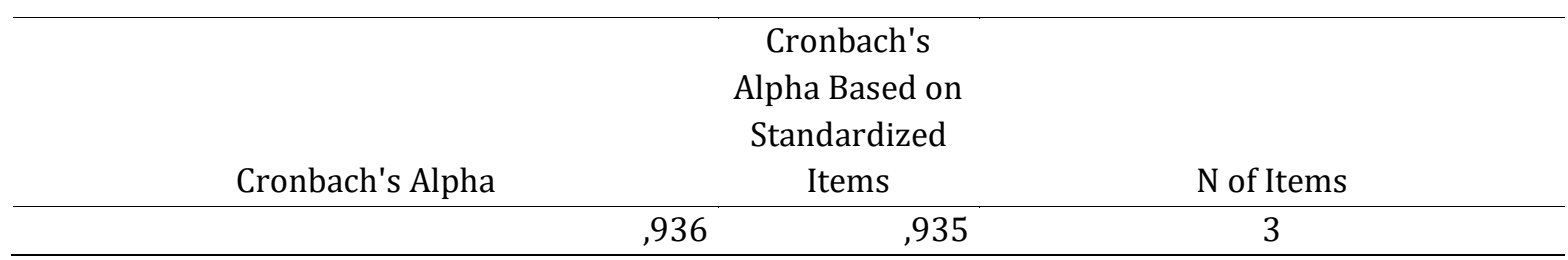

Sumber: Data diolah peneliti, 2020

Berdasarkan hasil uji reliabilitas diatas, dinyatakan bahwa Cronbach's Alpha kapabilitas pemasaran 0.900 lebih besar dari 0.6 dan Cronbach's Alpha kinerja pemasaran 0.935 lebih besar dari 0.6. Maka kapabiltas pemasaran (X) dan kinerja pemasaran (Y) dinyatakan reliable.

Hasil Analisis Data

Tabel 5. Hasil Uji Koefisien Korelasi

\begin{tabular}{llrr}
\hline & & $\begin{array}{c}\text { kapabilitas } \\
\text { pemasaran }\end{array}$ & kinerja pemasaran \\
\hline kapabilitas pemasaran & $\begin{array}{l}\text { Pearson } \\
\text { Correlation }\end{array}$ & 1 &, $712^{* *}$ \\
\cline { 2 - 4 } & Sig. (2-tailed) &, 000 \\
\cline { 2 - 4 } & $\mathrm{N}$ & 37 & 37 \\
\hline kinerja pemasaran & $\begin{array}{l}\text { Pearson } \\
\text { Correlation }\end{array}$ &, $712^{* *}$ & 1 \\
\cline { 2 - 4 } & Sig. (2-tailed) &, 000 & 37 \\
\cline { 2 - 4 } & $\mathrm{N}$ & 37 & \\
\hline
\end{tabular}

**. Correlation is significant at the 0.01 level (2-tailed).

Sumber: Data diolah peneliti, 2020

Berdasarkan data di atas, dinyatakan bahwa keterkaitan antara kapabilitas pemasaran (X) dan kinerja pemasaran (Y) berkorelasi karena nilai signifikansi sebesar 0.000 lebih kecil dari nilai signifikansi 0.05. Sedangkan tingkat hubungan antara kapabilitas pemasaran (X) dan kinerja pemasaran (Y) berkorelasi kuat karena nilai pearson correlation sebesar 0.712 .

Tabel 6. Hasil Koefisien Determinasi

\begin{tabular}{lrrrr}
\hline Model & $\mathrm{R}$ & R Square & Adjusted R Square & $\begin{array}{c}\text { Std. Error of the } \\
\text { Estimate }\end{array}$ \\
\hline 1 &, $712^{\mathrm{a}}$ &, 507 &, 493 & 2,35507
\end{tabular}

a. Predictors: (Constant), Kapabillitas pemasaran

b. Dependent Variable: kinerja pemasaran 
Sumber: Data diolah peneliti, 2020

Data diatas dapat dihitung dengan menggunakan rumus dari (Sugiyono, 2013):

Maka $\mathrm{Kd}=\mathrm{r}^{2} \times 100 \%$

$=0.712^{2} \times 100 \%$

$=50.7 \%$

Dari data diatas dapat dinyatakan bahwa nilai koefisien determinasi $\left(\mathrm{R}^{2}\right)$ sebesar $50.7 \%$. Yang artinya kapabilitas pemasaran memiliki pengaruh sebesar $50.7 \%$ terhadap kinerja pemasaran, dan sisanya yaitu sebesar $45.8 \%$ merupakan pengaruh dari faktor yang lain.

Tabel 7. Hasil Regresi Linear Sederhana Coefficients $^{\mathrm{a}}$

\begin{tabular}{|c|c|c|c|c|c|c|}
\hline \multirow[b]{2}{*}{ Model } & & \multicolumn{2}{|c|}{ Unstandardized Coefficients } & \multirow{2}{*}{$\begin{array}{c}\begin{array}{c}\text { Standardized } \\
\text { Coefficients }\end{array} \\
\text { Beta }\end{array}$} & \multirow[b]{2}{*}{$\mathrm{t}$} & \multirow[b]{2}{*}{ Sig. } \\
\hline & & $\mathrm{B}$ & Std. Error & & & \\
\hline 1 & (Constant) &,- 167 & 1,385 & &,- 120 & 905 \\
\hline & Kapabillitas pemasaran & ,704 & 117 & ,712 & 5,998 & 000 \\
\hline
\end{tabular}

a. Dependent Variable: kinerja pemasaran

Sumber: Data diolah peneliti, 2020

Berdasarkan data diatas maka peneliti memakai rumus (Sugiyono, 2013):

$\mathrm{Y}=\mathrm{a}+\mathrm{bX}$

$\mathrm{Y}=0.167+0.704 \mathrm{X}$

Diperoleh data dari hasil uji regresi linear sederhana yaitu skor $a=0.167$ dan b sebesar 0.704 . Jika kapabilitas pemasaran memiliki nilai nol maka kinerja pemasaran mempunyai skor berjumlah 0.167 serta skor regresi kapabilitas pemasaran yaitu 0.704 yang artinya pada peningkatakan kapabilitas pemasaran maka kinerja pemasaran pun akan meningkat.

Tabel 8. Hasil Uji Signifikansi (Uji T)

Coefficients $^{\mathbf{a}}$

\begin{tabular}{|c|c|c|c|c|c|c|}
\hline \multirow[b]{3}{*}{ Model } & & \multicolumn{5}{|c|}{ Standardized } \\
\hline & & Unstandardizec & Coefficients & Coefficients & & \\
\hline & & $\mathrm{B}$ & Std. Error & Beta & $\mathrm{t}$ & Sig. \\
\hline \multirow[t]{2}{*}{1} & (Constant) & -167 & 1,385 & & -120 & 905 \\
\hline & Kapabillitas pemasaran & 704 & 117 & 712 & 5,998 & ,000 \\
\hline
\end{tabular}

a. Dependent Variable: kinerja pemasaran

Sumber: Data diolah peneliti, 2020

Hasil data diatas menunjukkan bahwa terdapat hubungan yang signifikan antara kapabilitas pemasaran $(\mathrm{X})$ terhadap kinerja pemasaran $(\mathrm{Y})$ dengan nilai signifikan sebesar 0.000 yang artinya $0.000<$ 0.05. Dengan nilai tabel dapat diketahui dengan menggunakan rumus besaran derajat kebebasan (df) menurut (Sugiyono, 2013) yaitu tabel $=(\mathrm{df}=\mathrm{n}-\mathrm{k})$ maka $\mathrm{df}=37-1=36$. Dengan menggunakan distribusi tabel dengan taraf 0.05 didapatkan skor ttabel yang berjumlah 1.68830. Sehingga berdasarkan data tersebut dapat dikatakan bahwa thitung mempunyai jumlah lebih tinggi dibandingkan t tabel yaitu $5.998>1.68830$. Oleh sebab itu kapabilitas pemasaran $(\mathrm{X})$ memiliki pengaruh secara signifikan terhadap kinerja pemasaran $(\mathrm{Y})$. 


\section{Simpulan dan saran}

Berdasarkan penelitian yang telah dilakukan, maka didapatkan hasil dari menggunakan teknik analisis regresi linear sederhana yang menyatakan bahwa terdapat pengaruh kapabilitas pemasaran terhadap kinerja pemasaran. Hal tersebut didukung oleh hasil penelitian yang menyatakan data pada penelitian ini valid dan reliabel. Serta pada hasil uji signifikansi yang dihasilkan menyatakan bahwa terdapat hubungan secara signifikan pada kapabilitas pemasaran $(\mathrm{X})$ terhadap kinerja pemasaran $(\mathrm{Y})$.

Adapun saran bagi para pelaku usaha coffee shop yaitu harus mampu menerapkan dan menjalankan kapabilitas dengan langkah-langkah yang benar untuk mencapai kinerja pemasaran yang lebih unggul dari para competitor dengan bidang yang serupa. Pertama, perusahaan harus mampu memanfaatkan dan mengelola sumber daya yang dimiliki secara produktif dalam memasarkan produk yang dimilikinya. Kedua, perusahaan harus mampu membaca peluang yang bagus dengan menyesuaikan produk yang dipasarkan sesuai perkembangan pasar yang sedang berlangsung guna untuk menghindari kegagalan pada usaha yang dijalankannya. Ketiga, perusahaan harus memiliki pengetahuan yang lebih mengenai keinginan dan kebutuhan konsumen agar perusahaan dapat menghasilkan produk yang sesuai dengan kebutuhn dan keinginan konsumen. Sedangkan saran untuk peneliti yang akan melakukan penelitian dengan variabel serupa diharapkan untuk mampu menggunakan data dan informasi yang lebih akurat untuk mendukung penelitian agar hasil yang didapatkan pun lebih baik.

\section{Daftar Rujukan}

Chandra, Y. K. (2018). Formulasi Strategi untuk Meningkatkan Kinerja Lighthouse Coffee Brewery Bandung. Universitas Katolik Parahyangan.

Guo, H., Xu, H., Tang, C., Thompkins, Y. L., Guo, Z., \& Dong, B. (2018). Comparing the impact of different marketing capabilities: Empirical evidence from B2B firms in China. Marketing Capabilities, 2.

Hendrayati, H., \& Gaffar, V. (2016). Innovation and Marketing Performance of Womenpreneur in Fashion Industry in Indonesia. Procedia - Social and Behavioral Sciences, 219, 302. https://doi.org/10.1016/j.sbspro.2016.04.034

Hidayat, S., \& Murwatiningsih. (2018). Pengaruh Orientasi Pasar dan Kewirausahaan terhadap Kinerja Pemasaran melalui Kapabilitas Pemasaran pada UMKM Lanting di Kecamatan Kuwarasan Kabupaten Kebumen. Management Analysis Journal, 7(1), 98-109. https://doi.org/10.15294/maj.v7i1.19857

Hoiron, M., Wahyudi, E., \& Puspitaningtiyas, Z. (2018). Pengaruh Kapabilitas Pemasaran, Keunggulan Bersaing dan Budaya Organisasi terhadap Kinerja UKM (Usaha Kecil da Menengah) di Kabupaten Lumajang. Journal of Chemical Information and Modeling, 18(1), 39-40. https://doi.org/10.1017/CB09781107415324.004

Lieberto, S. (2019). Evaluasi Kinerja Bauran Pemasaran Coffee Shop Brnd Internasional dan Lokal (Studi Kasus di Mall Boemi Kedaton). Universitas Lampung.

Masrokan, Fathoni, A., \& Minarsih, M. M. (2016). Orientation Effect of Entrepreneurship, Marketing Knowledge Capacity and Marketing Performance of Marketing (Study Case At Cv. Rajawali Mas Semarang). Journal of Management, 2(2).

Mawu, I. P. P., Mandey, S. L., \& Tawas, H. N. (2016). The analysis effect of marketing knowledge competence and entrepreneurship orientation towards marketing capabilities and marketing performance (Study at industrial entrepreneur Wooden House City Of Tomohon). Jurnal EMBA, 4(3), 173-183.

Nurdianah, I. (2019). Analisis Pengaruh Orientasi Pasar, Inovasi Produk dan Orientasi Kewirausahaan Terhadap Keunggulan Bersaing dan Kinerja Pemasaran (Studi Pada Cafe Di Semarang). Universitas Diponegoro.

Palacios-Marqués, D., García, M. G., Sánchez, M. M., \& Mari, M. P. A. (2019). Social entrepreneurship and organizational performance: A study of the mediating role of distinctive competencies in marketing. Journal of Business Research, 101(June 2018), 429. https://doi.org/10.1016/j.jbusres.2019.02.004

Rasyidi, M. F., \& Sudjatno. (2016). Pengaruh Orientasi Kewirausahaan terhadap Kinerja Pemasaran Melalui 
Keunggulan Bersaing Sebagai Variabel Mediasi. Journal of Chemical Information and Modeling, 53(9), 4-5. https://doi.org/10.1017/CB09781107415324.004

Sugiyono. (2013). Metode Penelitian Administrasi. Bandung: Alfabeta.

Syarifuddin, U., Payangan, O. R., Muis, M., \& Amar, M. Y. (2019). Jurnal Mirai Management The Role of Marketing Capability Mediation in the Effect of Jurnal Mirai Management. 4(1), 106.

Wirawan, Y. R. (2017). Pengaruh orientasi pasar, orientasi kewirausahaan terhadap kinerja pemasaran UMKM batik di Kabupaten Jombang. EQUILIBRIUM : Jurnal Ilmiah Ekonomi Dan Pembelajarannya, 5(1), 58-60. https://doi.org/10.25273/equilibrium.v5i1.1006

Susanto, AB. 2014. Manajemen Strategik Komprhensif. Jakarta: Erlangga. 